\title{
Elena+ Care for COVID-19, a Pandemic Lifestyle Care Intervention: Intervention Design and Study Protocol
}

OPEN ACCESS

Edited by:

Hanife Rexhepi,

University of Skövde, Sweden

Reviewed by:

Angel Enrique Roig,

Silvercloud Health, Ireland

Tahreem Chaudhry,

University College London,

United Kingdom

*Correspondence: Joseph Ollier jollier@ethz.ch

Specialty section: This article was submitted to

Digital Public Health,

a section of the journal

Frontiers in Public Health

Received: 03 November 2020 Accepted: 20 September 2021 Published: 21 October 2021

Citation:

Ollier J, Neff S, Dworschak C, Sejdiji A, Santhanam P, Keller R, Xiao G,

Asisof A, Rüegger $D$, Bérubé $C$ Hilfiker Tomas L, Neff J, Yao J,

Alattas A, Varela-Mato V, Pitkethly A,

Vara MD, Herrero R, Baños RM,

Parada C, Agatheswaran RS, Villalobos V, Keller OC, Chan WS, Mishra $V$, Jacobson N, Stanger $C$, He X, von WyI V, Weidt S, Haug S, Schaub M, Kleim B, Barth J, Witt C, Scholz U, Fleisch E, Wangenheim Fv,

Car LT, Müller-Riemenschneider $F$,

Hauser-Ulrich S, Asomoza AN, Salamanca-Sanabria A, Mair JL and Kowatsch T (2021) Elena+ Care for COVID-19, a Pandemic Lifestyle Care Intervention: Intervention Design and Study Protocol.

Front. Public Health 9:625640. doi: 10.3389/fpubh.2021.625640
Joseph Ollier ${ }^{1 *}$, Simon Neff ${ }^{2}$, Christine Dworschak ${ }^{3}$, Arber Sejdiji ${ }^{2}$, Prabhakaran Santhanam ${ }^{1}$, Roman Keller ${ }^{4}$, Grace Xiao ${ }^{5}$, Alina Asisof ${ }^{1}$, Dominik Rüegger ${ }^{1}$, Caterina Bérubé ${ }^{1}$, Lena Hilfiker Tomas ${ }^{6}$, Joël Neff ${ }^{6}$, Jiali Yao ${ }^{4}$, Aishah Alattas ${ }^{4}$, Veronica Varela-Mato ${ }^{7}$, Amanda Pitkethly ${ }^{8}, M^{a}$ Dolores Vara ${ }^{9,10}$, Rocío Herrero ${ }^{9,10}$, Rosa $M^{a}$ Baños $^{9,10,11}$, Carolina Parada ${ }^{12}$, Rajashree Sundaram Agatheswaran ${ }^{13}$, Victor Villalobos ${ }^{14}$, Olivia Clare Keller ${ }^{1,15}$, Wai Sze Chan ${ }^{16}$, Varun Mishra ${ }^{17}$, Nicholas Jacobson ${ }^{18}$, Catherine Stanger ${ }^{18}$, Xinming He ${ }^{19}$, Viktor von Wyl ${ }^{20,21}$, Steffi Weidt ${ }^{22}$, Severin Haug ${ }^{23}$, Michael Schaub ${ }^{23}$, Birgit Kleim ${ }^{3}$, Jürgen Barth ${ }^{24}$, Claudia Witt ${ }^{24}$, Urte Scholz ${ }^{25,26}$, Elgar Fleisch ${ }^{1,4,15}$, Florian von Wangenheim ${ }^{1,4}$, Lorainne Tudor Car ${ }^{4,27}$, Falk Müller-Riemenschneider ${ }^{28,29}$, Sandra Hauser-Ulrich ${ }^{30}$, Alejandra Núñez Asomoza ${ }^{31}$, Alicia Salamanca-Sanabria ${ }^{4}$, Jacqueline Louise Mair ${ }^{4}$ and Tobias Kowatsch ${ }^{1,4,15}$

${ }^{1}$ Centre for Digital Health Interventions, Department of Management, Technology and Economics, Eidgenössische Technische Hochschule (ETH) Zurich, Zurich, Switzerland, ${ }^{2}$ Department of Management, Technology, and Economics, Eidgenössische Technische Hochschule (ETH) Zurich, Zurich, Switzerland, ${ }^{3}$ Department of Psychology, University of Zurich, Zurich, Switzerland, ${ }^{4}$ Future Health Technologies, Singapore-ETH Centre, Campus for Research Excellence and Technological Enterprise (CREATE), Singapore, Singapore, ${ }^{5}$ School of Medicine, Johns Hopkins University, Baltimore, MD, United States, ${ }^{6}$ Executive School of Management, Technology and Law, University of St. Gallen, St. Gallen, Switzerland, ${ }^{7}$ School of Sport, Exercise and Health Sciences, Loughborough University, Loughborough, United Kingdom, ${ }^{8}$ Sport, Exercise and Health Sciences, Edinburgh Napier University, Edinburgh, United Kingdom, ${ }^{9}$ Polibienestar Research Institute, University of Valencia, Valencia, Spain, ${ }^{10}$ Centro de Investigación Biomédica en Red de Fisiopatología de la Obesidad y Nutrición (CIBERObn) Physiopathology of Obesity and Nutrition, Instituto de Salud Carlos III, Madrid, Spain, ${ }^{11}$ Department of Personality, Evaluation and Psychological Treatment, Faculty of Psychology, University of Valencia, Valencia, Spain, ${ }^{12}$ Department of Psychology, Universidad San Buenaventura, Bogotá, Colombia, ${ }^{13}$ National Institute of Education, Nanyang Technological University, Singapore, Singapore, ${ }^{14}$ Interdisciplinary Center for Health Workplaces, University of California, Berkeley, Berkeley, CA, United States, ${ }^{15}$ Centre for Digital Health Interventions, Institute of Technology Management, University of St. Gallen, St. Gallen, Switzerland, ${ }^{16}$ Department of Psychology, University of Hong Kong, Pokfulam, Hong Kong, SAR China, ${ }^{17}$ Department of Computer Science, Dartmouth College, Hanover, NH, United States, ${ }^{18}$ Center for Technology and Behavioral Health, Geisel School of Medicine, Hanover, NH, United States, ${ }^{19}$ Business School, Durham University, Durham, United Kingdom, ${ }^{20}$ Epidemiology, Biostatistics and Prevention Institute, University of Zurich, Zurich, Switzerland, ${ }^{21}$ Institute for Implementation Science in Health Care, University of Zurich, Zurich, Switzerland, ${ }^{22}$ Department of Psychiatry, Psychotherapy and Psychosomatics, University of Zurich, Zurich, Switzerland, ${ }^{23}$ Swiss Research Institute for Public Health and Addiction, University of Zurich, Zurich, Switzerland, ${ }^{24}$ Institute for Complementary and Integrative Medicine, University Hospital Zurich, University of Zurich, Zurich, Switzerland, ${ }^{25}$ Applied Social and Health Psychology, Department of Psychology, University of Zurich, Zurich, Switzerland, ${ }^{26}$ Dynamics of Healthy Aging, University of Zurich, Zurich, Switzerland, ${ }^{27}$ Family Medicine and Primary Care, Lee Kong Chian School of Medicine, Nanyang Technological University, Singapore, Singapore, ${ }^{28}$ Department of Medicine, Saw Swee Hock School of Public Health, Yong Loo Lin School of Medicine, National University of Singapore, Singapore, Singapore, ${ }^{29}$ Center for Digital Health, Berlin Institute of Health and Charité, Berlin, Germany, ${ }^{30}$ Department of Applied Psychology, University of Applied Sciences Zurich, Zurich, Switzerland,

${ }^{31}$ Unidad Académica de Cultura, Universidad Autónoma de Zacatecas, Zacatecas, Mexico

Background: The current COVID-19 coronavirus pandemic is an emergency on a global scale, with huge swathes of the population required to remain indoors for prolonged periods to tackle the virus. In this new context, individuals' health-promoting routines are under greater strain, contributing to poorer mental and physical health. Additionally, individuals are required to keep up to date with latest health guidelines about the virus, 
which may be confusing in an age of social-media disinformation and shifting guidelines. To tackle these factors, we developed Elena+, a smartphone-based and conversational agent (CA) delivered pandemic lifestyle care intervention.

Methods: Elena+ utilizes varied intervention components to deliver a psychoeducationfocused coaching program on the topics of: COVID-19 information, physical activity, mental health (anxiety, loneliness, mental resources), sleep and diet and nutrition. Over 43 subtopics, a CA guides individuals through content and tracks progress over time, such as changes in health outcome assessments per topic, alongside user-set behavioral intentions and user-reported actual behaviors. Ratings of the usage experience, social demographics and the user profile are also captured. Elena+ is available for public download on iOS and Android devices in English, European Spanish and Latin American Spanish with future languages and launch countries planned, and no limits on planned recruitment. Panel data methods will be used to track user progress over time in subsequent analyses. The Elena+ intervention is open-source under the Apache 2 license (MobileCoach software) and the Creative Commons 4.0 license CC BY-NC-SA (intervention logic and content), allowing future collaborations; such as cultural adaptions, integration of new sensor-related features or the development of new topics.

Discussion: Digital health applications offer a low-cost and scalable route to meet challenges to public health. As Elena+ was developed by an international and interdisciplinary team in a short time frame to meet the COVID-19 pandemic, empirical data are required to discern how effective such solutions can be in meeting real world, emergent health crises. Additionally, clustering Elena+ users based on characteristics and usage behaviors could help public health practitioners understand how population-level digital health interventions can reach at-risk and sub-populations.

Keywords: chatbot, conversational agent (CA), digital coaching, digital health, coronavirus-COVID-19, gamification, mental health, pandemic lifestyle care

\section{INTRODUCTION}

The emergence of the COVID-19 coronavirus pandemic has created a global health emergency on an unprecedented scale (1). From the call to arms of research to tackle the pandemic, comes the challenge of delivering what the authors term pandemic lifestyle care. Pandemic lifestyle care concerns boosting population-level health during a period when many typical health promoting routines are severely disrupted and simple health promoting behaviors such as going for a walk or having personal space for relaxing hobbies have become much more difficult (2). Problems related to social isolation requirements have been rising; including flaunting of social distancing rules, lack of health promoting behaviors (physical activity, nutrition, sleep routines) and mental health issues (anxiety, loneliness) (3-5). In such circumstances, without additional intervention, individuals' health and well-being may deteriorate, particularly among at-risk groups with whom a lower level of health literacy, self-efficacy and/or access to resources exists already $(6,7)$. Additionally, without trusted resources and guidance readily and freely available at the population level, individuals may be more likely to ignore governmental guidelines, undermining public health efforts to tackle the pandemic (8).

In a variety of other behavioral health fields, digital health interventions utilizing smartphone technology have found success (9). In particular, conversational agents (CAs) have been applied to a variety of chronic disease contexts to help coach individuals and offer behavioral lifestyle interventions (10-12). Such applications have been shown to build working alliances with users (13), leverage benefits of gamification (14), utilize techniques from psychotherapy (e.g., cognitive behavioral therapy, motivational interviewing) (15) and enhance behavioral coaching in a manner similar to human-delivered coaching (11, 12, 16-19). Importantly, these interventions can be designed in a low-cost and accessible manner (20), so they have high potential to scale widely and offer a healthcare service to those whom may be lacking in treatment coverage $(21,22)$.

In this paper, we overview a digital health intervention that leverages findings from digital health research, combining varied theoretical and treatment approaches from different health domains into a single lifestyle intervention. The smartphone app, Elena+, named in honor of the Italian Nurse Elena Pagliarini, who was photographed exhausted from treating COVID-19 
patients, has been developed within a short-time frame by a team of researchers from around the world. It aims to capitalize upon the key findings from behavioral and digital health fields to implement current best practices for the public good during the current emergency in public health. The Elena+ app, freely available on both iOS and Android devices in a variety of nations (United Kingdom, United States, Switzerland, Ireland, Spain, Colombia, Mexico), utilizes a CA to interact with users and offers personalized coaching in lifestyle health topics which may be under strain during this COVID-19 period. Topics included are: (i) COVID-19 health information, (ii) physical activity, (iii) mental health (loneliness, anxiety, utilizing mental resources), (iv) sleep and (v) diet and nutrition. The project also lays the groundwork for future interventions by providing open-source intervention logic, content, and software, which may serve as a useful start-point for tackling other chronic and mental illness and/or provide the basis of a digital control condition for other digital health interventions.

In addition to its function as a publicly available coaching tool Elena + also doubles as a single-arm interventional study where we track individual progress through a series of psychoeducation and activity-based coaching sessions. The research aims of Elena + are as follows; first, we measure changes from baseline to follow-up health assessments for each topic; second, we track selfreported behavioral intentions and actual behaviors during the coaching progress, to see if these measures mediate the change process, as demonstrated by differences over time in a topic's main assessment health outcome as outlined above; third, we capture data related to the patient profile and usage experience, to understand how the success of Elena + may vary based on clusters of user/usage characteristics, that will enable better segmenting of the population and tailoring of approaches in future health interventions (23-25).

\section{INTERVENTION DESIGN}

Elena + is a smartphone app that uses a CA to lead individuals through a series of psychoeducation coaching sessions, comprising primarily of psychoeducational materials, behavior change activities, planning activities and intention/goal formation. Created rapidly to meet the emergent COVID-19 coronavirus pandemic, Elena+ delivers coaching sessions created by experts in their respective fields to attempt to reach in-need/atrisk sub-populations. A variety of intervention components have been utilized to: (i) foster engagement with the Elena+ app, and (ii) boost care potential in delivering pandemic lifestyle health outcomes. This harmonizes the intervention with current bestpractice from digital service and health intervention fields as far as possible, whilst considering current time and resource constraints in developing the app. For the intervention design of Elena+, we combined various theory-driven and practiceled approaches from different fields and tailored coaching materials accordingly. In total 43 coaching sessions have been created on the topics of: COVID-19 health information, physical activity, loneliness, anxiety, utilizing mental resources, sleep, and diet/nutrition. A full overview of coaching topics and subtopics within them is given in section Coaching Topics.

The conceptual model in Figure 1 overviews the driving engine of the Elena+ intervention, outlining how intervention components target: (i) theoretical constructs, (ii) antecedent causes of behavioral intentions, and (iii) behavioral activation. The Elena+ Engagement Intervention Components outline design choices for the app usage experience, the CA, and the promotional strategy aimed to promote positive perceptions of the Elena+ app usage experience. As stated in both Theory of Planned Behavior (TPB) (26) and Technology Acceptance Model (TAM) (27), once sufficiently positive evaluations of the app usage experience are created, users will intend to use the app, and thus exhibit a state of engagement. Once engaged, individuals are then able to benefit from the Lifestyle Intervention Components of: (i) psychoeducation, (ii) behavior change activities, and (ii) planning activities in the respective seven coaching topics. This in turn influences the perceived usefulness of the coaching sessions, and by completing further psychoeducational coaching content and activities, individuals will exhibit greater self-efficacy and feelings of social support (28). This empowers coachees to set behavioral intentions and follow them through as "actual behaviors" in their daily lives, during a period of reflection, implementation, and experiential learning as part of the coaching process (29). As individuals apply psychoeducation and behavior change/planning activities into their own lives, health outcome assessment scores are expected to improve leading to positive reinforcement loop via greater engagement with the Elena+ app. The intervention is therefore unique in its broad approach to target multiple facets of an individual's lifestyle, and varies from other CA interventions which typically focus on a single health domain but in greater depth (10) representing both a novel treatment and research opportunity in digital public health efforts (30).

\section{Intervention Components} Engagement Intervention Components Interpersonal Style of the Elena + CA

The working alliance represents the relationship quality between patients and healthcare professionals, and is robustly linked to treatment success in both offline and digital settings (13, 3133). Comprising of task, bonds and goals (34) shared between coach and coachee, it is a key predictor of health behavior and attitude change (35). In digital contexts it can be boosted by creating interactions that adhere to principles outlined in positive psychology coaching and motivational interviewing (18, 35-37) such as leveraging interpersonal cues (38), expressing empathy (39), and eliciting change talk (29, 37, 40, 41). For Elena + we utilize past findings such as blending both social and task-oriented dialogue (42), depiction of a pictorial avatar representation for the agent $(38,43,44)$, and utilization of some backstory for the CA $(45,46)$ (i.e., it is a digital representation of a real nurse like Elena that helps fight COVID-19). In this vein, to help nurture a coaching atmosphere, terms such as "menu" or "next time you use the app" are avoided, and terms relevant to face-to-face communication such as "coaching choices" or "in your next coaching session" are utilized by the CA. 


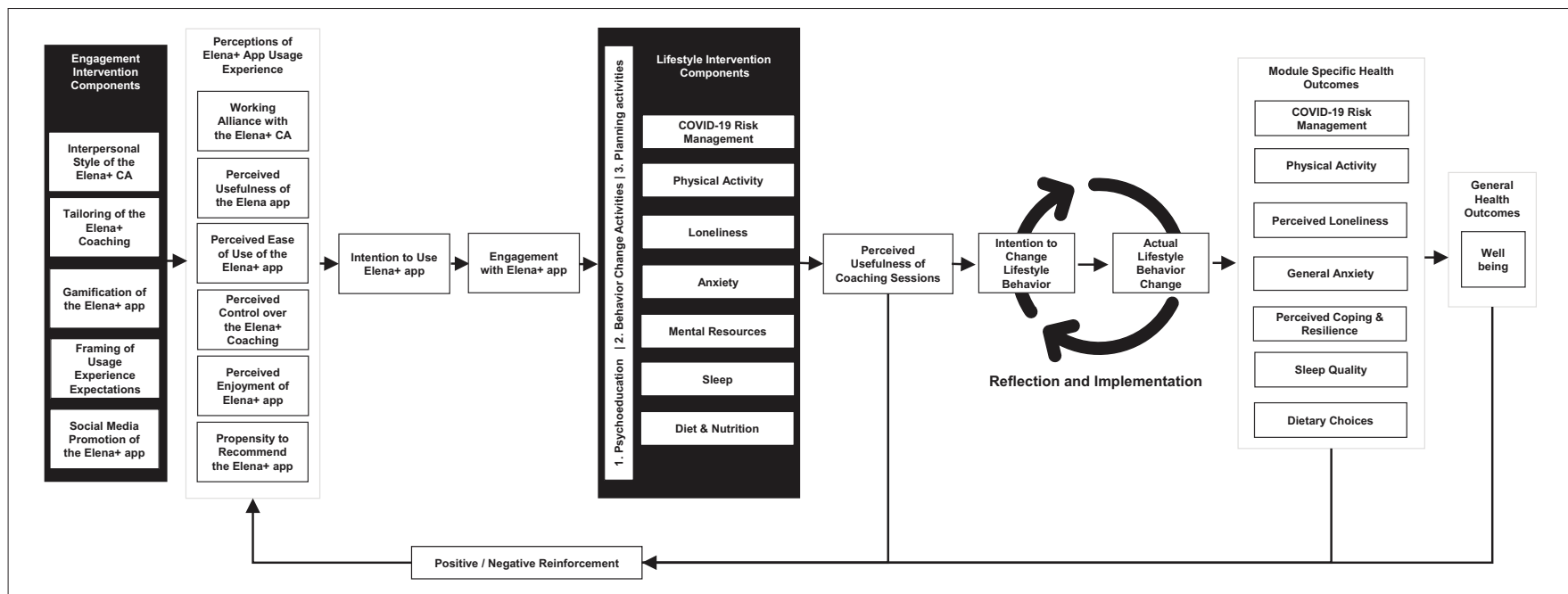

FIGURE 1 | Elena+ conceptual model.

\section{Personalization of Elena + Coaching}

Personalization is a key factor eliciting trust, feelings of familiarity and adoption of technologies (47) and in turn positively influences the user experience (48). Efforts were therefore put into giving user choice and autonomy as far as possible throughout the experience, and using non-forceful language in line with self-determination theory and motivational interviewing (49-51). Examples include the selection of your digital coach (Elena or Elliot), use of an assessment quiz to make topic recommendations, and the opportunity to set personalized goals related to behavior change. Additionally, Elena+ also offers "on demand coaching" i.e., individuals may continue coaching at any time they wish, and there are no limits on content availability which differs from other digital health interventions which limit content available per day.

\section{Gamification}

Gamification i.e., "gaming elements used outside of games" is a key factor in motivating users (52) and creating an engaged state $(14,53)$. It has been successfully used in mental health and psychiatry care (52) by applying gaming mechanics to non-game contexts (45), for example, winning points to add instrumental and experiential value to activities (54).

For the current Elena+ intervention, we utilize gamification concepts by rewarding individuals with badges to symbolize progress through the app, and awarding hearts for coaching session/assessment question completion, helping to evoke behavioral economic aspects related to avoiding losses and maximizing gains (55). Surprise bonus hearts are also awarded during the intervention, which has been found to instill additional motivation via random variable scheduling of rewards (56). These bonuses may be awarded for timely completion of all intervention content (whereby timely consists of completing 12 coaching sessions per day, requiring $\sim 70$ days to complete). This serves as a control mechanism to nudge coachees to complete Elena+ in an optimal time frame so that users' can adequately process and apply coaching content to their daily lives (see section Intervention Timeframe). Additionally, hearts are framed to coachees with a social message during the intervention onboarding; "hearts help our healthcare heroes," with further details explaining to coachees that by earning hearts, individuals are following a path of action that helps frontline carers safe by ensuring healthcare systems are not overloaded. This is to strengthen altruistic and social motivation for using the app, which has been linked to internalized values and intrinsic forms of motivation $(57,58)$.

\section{Framing of Usage Experience Expectations}

Positively framing user expectations on usage experience enables feelings of transparency and value co-creation (59), and has been linked to increased behavioral intentions (60), relationship formation (61), and satisfaction (62). In Elena+ "onboarding" disclosures (i.e., disclosures from the CA related to service experience) are utilized during the first interactions and prior to selection of coaching topics for the first time a topic category is chosen, orienting coachees to the coaching process. Additionally, research has shown that failure to disclose privacy information in a transparent way may cause individuals to drop-out from digital services and cause poor trust in platforms (41). A recent review of CA use in digital health interventions has recommended disclosing privacy information transparently to avoid such complications (13). In this spirit, the Elena+ CA briefly outlines how information is kept safe and stored in an anonymous fashion within the chat, in addition to the minimum legal requirements of displaying the terms and conditions.

\section{Social Media Promotion of the Elena + App}

Social media has been harnessed both as a tool to recruit participants (63) as well as for health promotion and behavior change (64). For the current intervention we created social media accounts on Facebook, Twitter, Instagram, and LinkedIn, as well as a separate website. At present the Facebook Ad Manager 
platform is used actively for both promotional and recruitment purposes through use of advertisements. As the project evolves, we may experiment with use of other platforms.

\section{Lifestyle Intervention Components Psychoeducation}

Health literacy has been defined as "the cognitive and social skills which determine motivation and ability of individuals to gain access to, understand and use information in ways which promote and maintain good health" (65). On the population level, promoting patient health literacy is linked to reduced chronic illness prevalence, reduced early mortality and effective use of health services (66), while on a patient level, it represents the "personal and relational factors that affect a person's ability to acquire, understand and use information about health and health services" (67).

In Elena+ psychoeducation is employed "to enhance the likelihood of provision and receipt of effective and collaborative health care" (66) and boost patients' health literacy. As the app is aimed broadly at the general public, several steps have been taken to better ensure the understandability of psychoeducational material (68). These include; writing health information using layman's terms where possible, using specific terms with definitions, and allowing individuals the option to enquire for further explanations and definitions, whilst also ensuring the coaching experience is not unnecessarily slowed for high literacy coachees (69). An additional consideration was the division of materials across the intervention into beginner and intermediate levels (where appropriate) to better match individual knowledge, experiential background and/or motivational state (as detailed in section Coaching Topics).

\section{Behavior Change Activities}

To support the psychoeducation efforts that influence behavioral intention formation $(70,71)$, behavior change activities are utilized as part of the coaching and change process $(29,72)$. These activities are taken from a variety of specific fields (motivational interviewing, cognitive behavioral therapy) and adapted to the digital CA coaching context (18). Examples of activities used include the " 5 good things technique," cognitive restructuring, mindfulness/breathing exercises, anxiety diaries and more (40, $73,74)$ depending on the coaching topic covered (see section Coaching Topics). This helps bring psychoeducational material to light by outlining practical techniques individuals can utilize to manage their health in the short term, as well as teaching longer term coping skills to manage symptoms in new contexts.

\section{Planning Activities}

Behavioral supports such as planning activities can be effective in simplifying decision making across the patient health literacy spectrum, helping to set clear and specific goals (75). They are particularly important for low health literacy groups whom may struggle in comprehending and applying information to their own lifestyles without support (76). In Elena+ planning activities are utilized to aid goal formation, for example, in the physical activity module; goal setting outcomes, goal setting behaviors, discrepancy between current behavior and idealized outcomes are discussed. Individuals can also set and review physical activity goals in line with the Capability, Opportunity, Motivation, Behavior (COM-B) approach (77). Additionally, at the end of each session, individuals are encouraged to set behavioral intention(s) based on content covered, offering concrete next steps to facilitate their behavioral activation (78). As the danger of the "intention-behavior" gap exists (79-81), individuals' actual behaviors are followed up upon via messaging 4-10 days following completion of a coaching session. This helps sync with extant research on using situational cues (82), and short text-message reminders of action-plans (83), to increase the effectiveness of goal/behavior planning activities.

\section{Coaching Topics}

In the Elena+, individuals may complete coaching content in several different health topics. These represent the pandemic lifestyle areas where aforementioned techniques detailed in the intervention components (such as psychoeducation or planning activities) are applied to each health domain. For any given overarching coaching topic (e.g., Anxiety), a variety of sub-topics (e.g., "Breathing Away Anxiety") are available for completion with the CA, each lasting $\sim 5-10$ min (see Table 1). Coaching for each subtopic content was created by an international and interdisciplinary team of domain health experts during April and May 2020, based on scientific findings and their expertise, and is continually reviewed regarding any new COVID-19 guidance from the World Health Organization (WHO).

For the design of coaching content, we followed relevant theoretical approaches. For the topics of COVID-19 health information, sleep, diet and nutrition, and physical activity a Health Action Process Approach (HAPA) inspired design was used and we divided materials between beginner and intermediate + difficulty levels so that Elena + users with a greater degree of knowledge, experiential background and/or motivation (as discerned during a gamified health assessment, detailed in section Intervention Logic) are directed ahead to intermediate + coaching materials to better promote their learning and engagement $(84,85)$. Presently, diet and nutrition contains three beginner coaching sessions with further intermediate + materials planned. For the mental health topics (anxiety, loneliness, utilizing mental resources) intervention materials were conceptualized along a series of continua (rather than divided into discrete categories of beginner and intermediate + ) following evidence-based transdiagnostic treatment in mental health (86-88). Lastly, in planning all topics, we also took inspiration from the Behavioral Change Wheel and COM$B$ model of behavior change (77), for example using the APEASE criteria to identify intervention functions and behavior change techniques suitable to deliver the COM-B components of psychological capability, reflective motivation, automatic motivation, and social opportunity (77). An overview of the rationale for including each coaching topic and specific content is given in the current section.

\section{COVID-19 Health Information}

Having individuals within society enact COVID-19 guidelines widely is vital for tackling the virus (8), however this requires 
TABLE 1 | Coaching topic overview.

\begin{tabular}{|c|c|c|}
\hline Module topic & Beginner coaching subtopics & Intermediate+ coaching subtopics \\
\hline \multirow[t]{5}{*}{ COVID-19 } & What is COVID-19 and what are coronaviruses? & What are pandemics and why do they occur? \\
\hline & What are the symptoms and how do they differ from the flu? & How and when should I self-isolate? \\
\hline & How is COVID-19 coronavirus spread? & How can I get tested/diagnosed for COVID-19? \\
\hline & What groups are most at risk? & Are hospitals/medical facilities safe to visit? \\
\hline & How can we prevent the spread? & More advanced information on preventing transmission/catching COVID-19 \\
\hline \multirow[t]{4}{*}{ Physical activity } & What is physical activity and how much should I do? & How does physical activity affect my immune system? \\
\hline & What are the benefits of being active? & Safety, inspiration and fitness goals during COVID-19 \\
\hline & Getting more active during COVID-19 & How can I improve my fitness? \\
\hline & Safe exercising during COVID-19 & How can I maximize the benefits of physical activity? \\
\hline \multirow[t]{5}{*}{ Sleep } & Why is sleep important? & What is sleep hygiene? \\
\hline & How does healthy sleep help to protect me from COVID-19? & What hinders and helps good sleep? \\
\hline & Is good sleep important for my mental health? & How does poor sleep put me at risk for COVID-19? \\
\hline & What happens if I do not sleep well? & How can I manage to sleep well during confinement? \\
\hline & Can anxiety, stress and poor sleep cause COVID-19? & \\
\hline \multirow[t]{3}{*}{ Diet and nutrition } & Unhealthy food hazards & \\
\hline & The positive effects of a nutrition-rich diet & \\
\hline & Preparing meals with the daily dozen & \\
\hline \multirow[t]{5}{*}{ Anxiety } & What is anxiety and why is it hard to control? & \\
\hline & COVID-19, risk perception and anxiety & \\
\hline & How can I control my anxiety? & \\
\hline & Breathing away anxiety & \\
\hline & Confinement and anxiety & \\
\hline \multirow[t]{3}{*}{ Loneliness } & What is loneliness? & \\
\hline & Can Ioneliness make you sick? & \\
\hline & How can we deal with loneliness? & \\
\hline \multirow[t]{5}{*}{ Mental resources } & The fundamentals of mental resources & \\
\hline & The functions of mental resources & \\
\hline & The neuroscience behind mental resources & \\
\hline & Identifying our mental resources & \\
\hline & Activating our mental resources & \\
\hline
\end{tabular}

a large information processing burden on the part of the individual, whom must vigilantly pay attention to developments. Additionally, one-way media channels must compete with a more interactive social media platforms, which presently contains the danger of misinformation and "fake news" (8), for example, stories claiming $5 \mathrm{~g}$ mobile-phone networks caused the COVID-19 outbreak (89). Certain individuals in traditionally at-risk groups lower in self-efficacy and/or health-literacy may be particularly vulnerable for a failure to follow guidelines $(6,90)$ and more susceptible to "fake news" stories (91). To tackle these factors, Elena+ offers the COVID-19 health information module based on trustworthy and legitimate sources including the core guidelines and information provided by the World Health Organization and other governmental bodies and/or charities/agencies.

\section{Physical Activity}

Current restrictions on individuals' lifestyles (gym closures, requirements to stay indoors, social distancing guidelines) are making physical activity levels more challenging to maintain
(92). This may pose a particular issue for individuals that prefer socially oriented exercise contents $(93,94)$ (i.e., exercise classes, running with friends) and now experience a lack of motivation or structured guidance for solo exercise. The physical activity (PA) module delivers a variety of sub-topics and enables the development (or continuation) of physical activity routines to contribute to strengthened immune systems and improved population health. By providing information on suitable activity types (aerobic, strength, mixed) that individuals can perform whilst maintaining social distancing guidelines, we influence individual outcome expectancies, self-efficacy and goal setting to facilitate behavioral activation, and stay active while adhering to public health guidelines.

\section{Sleep}

Sleep is known to contribute to overall immune system health (95) and bolster mental health resilience (96), however, the pandemic creates additional stressors (such as increased use of electronic devices, less time spent physical active, additional stress) which has deleterious effects on sleep quality $(97,98)$. 
The sleep module therefore employs multicomponent cognitive behavioral therapy as recommended by the Standards of Practice Committee (SPC) of the American Academy of Sleep Medicine (AASM) (99) as an effective, non-pharmacological intervention to improve sleep hygiene $(100,101)$. Sleep education in Elena+ includes: (i) information about the neurophysiological components of sleep from the vigilance model (102), (ii) the different stages of sleep and associated oscillatory patters, (iii) the role of certain neurotransmitters (e.g., serotonin, dopamine) which help with the transition of said stages (102), as well as, (iv) explaining how sleep is regulated by the circadian rhythm (Process C) and the sleep-wake homeostasis (Process S) from the two-process model (103). Other sleep-relevant recommendations such as improving physical activity, nutrition, creating a sleep routine or reducing device use prior to bed are also discussed $(97,100,104)$.

\section{Diet and Nutrition}

Diet and nutrition is known to contribute to the immune system and physical health generally (105). In the current period of COVID-19, ensuring individuals eat well and maintain a nutritional diet is key in boosting overall population health (106). Eating habits often become routine (107), and for many individuals their current eating routines will be in a period of flux; additional time at home may provide the chance to reassess previous eating habits, and with sufficient guidance, allow individuals to develop new routines and exerting greater control over dietary choices. The module therefore functions to provide nutrition and diet information and support individuals in making healthy choices; influencing outcomes expectancies and selfefficacy regarding food and diet choices based upon guidelines from the World Health Organization (108) and publications recommending plant-centered diets in managing and preventing chronic diseases (109-111).

\section{Mental Health}

During the pandemic strains on mental health have been exhibited; with individuals experiencing periods of increased isolation, uncertainty regarding their employment and safety, and less freedom to enjoy stress-reducing activities $(112,113)$. Without guidance therefore, there exists the ever present danger that such stressors may lead to unhealthy coping strategies, creating a negative feedback loop and increased strains upon mental health (112). While mental health has previously been considered a delicate topic for automated agents to address, there exists a growing literature body on utilizing CAs to deliver high quality care $(15,19,114)$. Contributing to this emergent stream of research, the mental health module offers the topics of: (i) anxiety, (ii) loneliness and (iii) discovering mental resources.

\section{Anxiety}

A CBT-inspired approach was used for anxiety materials, focusing on dysfunctional thoughts that affect behavior and functioning and emotion-regulation (115-117), whereby emotion regulation refers to decreasing the experiential and behavioral aspects of negative emotions (73). Some emotional regulation strategies utilized in Elena+ involve: (i) situation election (e.g., choosing not to watch or read news about COVID19 throughout the day, only once or twice daily), (ii) attentional deployment (e.g., scheduling and directing attention to enjoyable activities activities), (iii) cognitive change (e.g., modifying how one appraises a situation so as to alter its emotional significance), and (iv) response modulation (e.g., using deep-breathing relaxation techniques) (73). In this way, the anxiety module has been developed considering the strategies recommended by Sanderson et al. (118), offering an evidence-based treatment for anxiety tailored toward pandemic circumstances.

\section{Loneliness}

Loneliness has been defined as the discrepancy between an individual's preferred and actual social relations (119). Prior to COVID-19 outbreak, loneliness was a major public health concern and had been linked to increased morbidity and mortality risks (120-122). As typical treatment for alleviating loneliness such as increasing opportunities for social interaction (123) is not presently possible, these issues are addressed by our intervention in several steps: (i) by discussing opportunities for social interaction compatible with COVID-19 recommendations, (ii) by implementing psychoeducation to make users aware of the increased risk of feeling lonely and its negative impact on wellbeing (124), and (iii) directly addressing these consequences in behavior change activities such pleasant activity scheduling (125).

\section{Mental Resources}

Coping resources have been found to reduce psychological distress and buffer the consequences of stressful life events $(126,127)$ however if individuals underestimate their potential to cope with stress, no adaptive coping strategies will be developed. Emotion-focused coping in Elena+ therefore adjusts an individual's emotional response to the varied and subjective stressors affecting them, and focuses on regulating negative emotional reactions to these stressors, following the Transactional Model of Stress and Coping by Lazarus and Folkman (128). This is done by using various cognitive and behavioral skills, such as positive-thinking, reframing, or distraction (e.g., defining a resource to enjoy such as writing down positive memories, utilizing relaxing space in the home or garden) with downstream consequences of boosting an individual's perceived competence and self-efficacy to manage stressors (129).

\section{TECHNICAL IMPLEMENTATION}

\section{Intervention Logic}

The intervention logic for Elena+ is displayed in Figures 2, 3. Figure 2 shows the coachee process from download of the Elena + app to completing their first coaching session.

Referring to Figure 2 (and to the diagram numbers), the intervention starts off by "exploring the coaching agenda" whereby: (1) coachees are onboarded to the Elena+ experience (i.e., explanations of the coaching service are given and expectations framed, privacy protection steps are mentioned) and simple demographics are taken, and (2) the coaching agenda is explored in greater depth where coachees input their coaching 

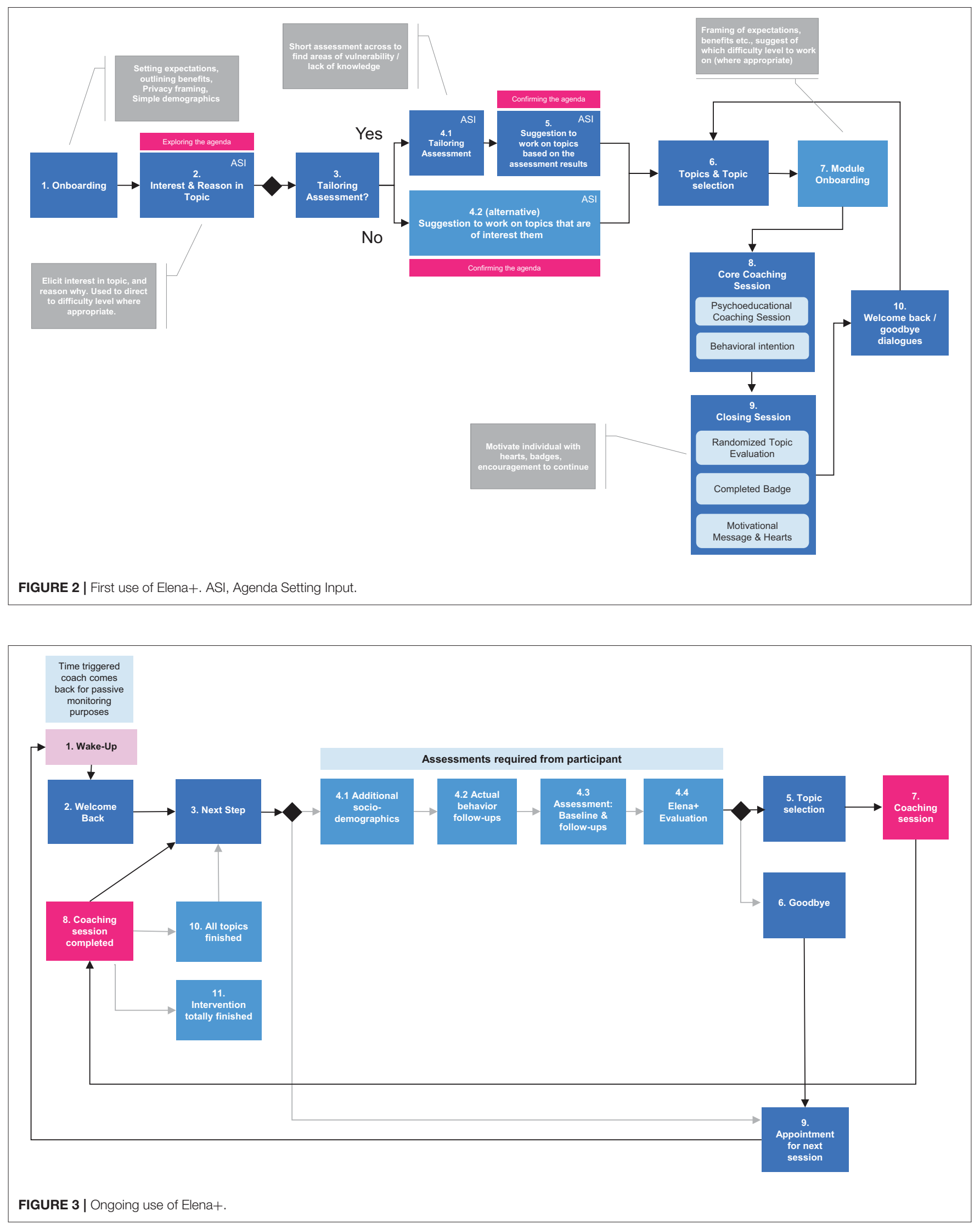
interest in the various coaching topics and optionally select from reasons why (e.g., the user states they are curious, or they have been struggling with a given topic), which is used as an input to tailor coaching content later between both topics and difficulty where appropriate. During the "confirming the agenda" stage (3-5) individuals are strongly encouraged to take the tailoring assessment which functions as a type of gamified quiz (4.1) by outlining benefits (i.e., the app will be better tailored to them and their circumstances). Based on the assessment results from this quiz, individuals are given a suggestion of which coaching topics are likely to be of most use to them and then they go to topic selection. Individuals may also opt to skip the assessment (4.2) to preserve user autonomy and go straight to topic selection (6). Following topic selection (6), individuals are directed to the module onboarding (7) which gives an overview of the benefits of taking this series of coaching topics and baseline assessment measures are taken, so that individuals pre and post health outcome scores from using coaching materials can be assessed at a later time. The module onboarding also occurs only once, on the first-time starting a given module.

A topic is then completed by an individual (8) which contains psychoeducation and behavior change/planning activities as appropriate, and a behavioral intention may be set based on the materials covered in that session. Typically, a single coaching session lasts from between 5 and $10 \mathrm{~min}$. After this, individuals move to (9) closing session, where a badge is awarded for specific topic completion, hearts are also awarded for progress in the Elena+ coaching experience and a randomized session evaluation may occur (asking individuals how they perceived the coaching session). Lastly, individuals move to the (10) welcome back/goodbye dialogue where individuals can choose to: (i) continue coaching with another topic selection, (ii) set a date for the next coaching session, (iii) choose to "wake up" the coach to continue coaching at a non-scheduled time (e.g., before their next appointment).

Figure 3 shows ongoing use, whereby, individuals begin at the (2) "welcome back" dialogue (which can be coach or coachee triggered) and following this typically proceed to the next step (3) which may state that some questions (assessments) are required from the participant. If needed, the participant completes the (4) assessments, and typically proceeds to (5) topic selection and then (7) completes a coaching session, and when finished continues to (8) the closing session dialogue, subsequently choosing (3) next steps they would like to take. However, following the assessments, individuals may choose to also (6) finish, which may typically be the case when an individual has just completed a coaching session and does not wish to start another. This may also occur when an individual has completed all coaching sessions but continues to use Elena+ for behavioral reminders or to earn hearts to combat the pandemic (i.e., "hearts help our healthcare heroes" - as highlighted in Table 2). In either case, users would then go to (9) the "appointment for next session" dialogue (ANS) to set a date when Elena should come back to them for more coaching, and after this is confirmed a (1) wake up button is displayed where the user can trigger more coaching at any time. If the coachee does not select the wake-up button (1) then the coach will restart dialogue at (2) with the welcome back dialogue at the appointed time.

Lastly, the (10) "all topics finished" dialogue is triggered when an individual has completed all coaching topics, a congratulations message and additional hearts and summary of achievements are given. Individuals are given motivation for continuing to use the app (i.e., that it can keep you on track with intentions you have set) and a social motivation (answering assessment helps combat COVID-19). When all topics, assessments and actual behavior follow-ups are completed by individuals, the (11) "intervention totally finished" dialogue occurs, and the intervention ends for this participant.

\section{Development}

Elena+ was developed during Summer 2020 using MobileCoach (www.mobile-coach.eu), an open source software platform, available under the industry and academic-friendly Apache 2 license (137) for smartphone-based and CA-delivered digital health interventions and ecological momentary assessments (138, 139). MobileCoach allows intervention authors to design fully automated data collection protocols and interventions consistent with the talk-and-tools paradigm (140). It offers a chat-based interface with free text/number input and predefined answer options that are used to simulate conversational turns commonly applied in counseling sessions with health professionals and their clients (the "talk"). The Elena app also delivers a wide range of "tools," i.e., various micro-interventions such as reminders or psychoeducational video clips. Against this background, Elena + can complement existing video mediated or personal counseling sessions with general practitioners, lifestyle coaches or mental health coaches, and can also reach individuals in a scalable way when a personal coaching approach is neither appropriate, nor geographically accessible, or beyond financial limits and personal resources (e.g., in epidemic times of isolation and social distancing). The intervention content for Elena + is also available under the Creative Commons license CC BY-NC-SA, a non-commercial license that allows free access to content and requires the sharing of new developed features with the original intervention authors, to encourage scientific sharing and collaboration internationally. A screencast is available on the project website www.elena.plus as well as in the Supplementary Material.

\section{EVALUATION OF ELENA+ \\ Sample and Data Collection}

The Elena+ app is listed on both Apple/Google app stores as "Elena+ Care for COVID-19" (Spanish: "Elena+ cuidados ante la COVID-19") and may be used on both iOS and Android devices in the United Kingdom, Ireland, Switzerland, and on Android devices only at present in the United States, Spain, Mexico, and Colombia with further launch countries planned. The app is listed in the search index with the following keywords (and Spanish equivalents): COVID-19, coronavirus, mental health, sleep, exercise, diet, nutrition, coaching, and thus a natural amount of organic recruitment occurs by individuals searching for these terms. In addition, we utilize the Facebook 
TABLE 2 | Intervention components.

\begin{tabular}{lll}
\hline Intervention components $\quad$ Brief description & Theoretical background
\end{tabular}

\section{Engagement intervention components}

Interpersonal style of the Elena+ CA

Tailoring of the Elena+ coaching

Gamification of the Elena+ app

Framing of usage experience expectations In line with services marketing, information systems research,

Social media promotion of the Elena+ app Advertisements and posts are used to promote, recruit and

\section{Lifestyle intervention components}

Psychoeducation

Behavior change activities

Planning activities and human-computer interaction research, we take inspiration in shaping first encounters through use of onboarding individuals regarding usage expectations and privacy matters. shape perceptions of the Elena+ app to adults $18+$. At the time of writing, Facebook is actively used, we also have reserved Twitter, Linkedln and Instagram accounts.

Interpersonal and empathetic communication in line with coaching literature to increase relational between coach and coachee intervention. Examples include the assessment quiz making tailored recommendations, self-selection of coaching topics, being available $24 / 7$ for users between coaching session appointments. In line with coaching literature, individual choice and autonomy are preserved throughout, which also includes only making suggestions in a non-forceful manner.

Gamification in the form of winning hearts and badges for demonstration of progress and motivational reinforcement

Coaching sessions centered around health literacy information delivered by domain experts and put into an easy to understand format for those of varied health literacy levels.

Activities from certain coaching traditions as relevant to the domain (e.g. Cognitive Behavioral Therapy, Motivational Interviewing etc.) are used to put health information in context in the coachees life.

At the end of a coaching session, individuals are encouraged to set a behavioral intention. This synthesizes information participants may have learnt and by setting an intention, crystalizes it to a concrete next step, helping in the behavioral change process. Additionally, planning activities may be used during sessions with regard to straightforward plans to help implement behavioral intentions.
Working Alliance, Horvath and Greenberg (130); Establishing and Maintaining Long-Term Human- Computer Relationships, Bickmore et al. (32).

Self-determination Theory, Ryan and Deci (49); Positive psychology coaching, Passmore and Oades (29)

Serious Games and Gamification for Mental Health, Fleming et al. (52); Gamification for Health Promotion: Edwards et al. (131).

Role Theory in the Service Encounter (132); The Onboarding Effect (133) Cardoso 2017; Communication Privacy

Management Theory, Metzger (134)

Using Social Media For Health Research, Arigo et al. (63); Harnessing Social Media for Health Promotion and Behavior Change, Korda and Itani (64)

Health Promotion, Nutbeam and Kickbusch (65), Health

Literacy, World Health Organization (135).

The Psychology of Coaching and Mentoring, Passmore et al. (37)

Health Action Process Approach, Schwarzer (85), Gollwitzer (136).

(


TABLE 4 | Timing schedule of assessment and actual behavior questions in days.

\begin{tabular}{|c|c|c|c|c|c|c|c|c|c|c|}
\hline \multirow[t]{2}{*}{ Topic } & \multicolumn{4}{|c|}{ Actual behavior follow-ups: } & \multicolumn{5}{|c|}{ Assessments: } & \multirow[t]{2}{*}{ \pm Days } \\
\hline & 1st & 2nd & 3rd & 4th & 1st & 2nd & 3rd & 4th & 5 th & \\
\hline Anxiety & 7 & 21 & 35 & 77 & 14 & 28 & 42 & 84 & 126 & 0 \\
\hline Mental resources & 8 & 22 & 36 & 78 & 15 & 29 & 43 & 85 & 127 & +1 \\
\hline Loneliness & 9 & 23 & 37 & 79 & 16 & 30 & 44 & 86 & 128 & +2 \\
\hline Sleep & 10 & 24 & 38 & 80 & 17 & 31 & 45 & 87 & 129 & +3 \\
\hline Physical activity & 6 & 20 & 34 & 76 & 13 & 27 & 41 & 83 & 125 & -1 \\
\hline Diet and nutrition & 5 & 19 & 33 & 75 & 12 & 26 & 40 & 82 & 124 & -2 \\
\hline $\begin{array}{l}\text { COVID-19 } \\
\text { info }\end{array}$ & 4 & 18 & 32 & 75 & 11 & 25 & 39 & 81 & 123 & -3 \\
\hline
\end{tabular}

must: (i) be aged 18 years or over, (ii) accept the app terms and conditions and (iii) give informed consent for study purposes. If any of these are not true, individuals are screened out early in the Elena+ dialogue. All procedures were in accordance with the ethical standards of the 1964 Helsinki declaration and its later amendments.

Care was put into reducing unintended negative consequences. For example, during the tailoring assessment, individuals that score highly in the General Anxiety Disorder scale or Patient Health Questionnaire or $(\geq 5)$ are recommended by the CA to seek human assistance (e.g., from their family doctor or a mental health charity) (141). As we gather no personally identifying information (as part of privacy protection measures) we cannot report these individuals who may benefit from human intervention to medical authorities nor compel individuals to seek out care. However, it was decided not to exclude these individuals from further use of the app, as while receiving human support would be optimal, receiving assistance through the Elena + app is still better than receiving no support whatsoever. Regarding unintended consequences related to data safety, in the highly unlikely case of an attack on the Elena+ servers, user data will remain anonymous as we collect no personally identifying data, only simple non-identifiable information such as user gender, age, "nickname" and the language version in use. It could be possible that users specify their full name as their "nickname," however, without further personally identifiable information collected (such as telephone number or e-mail address), it is extremely improbable individuals could be personally identified. Lastly, while efforts were put into making informed consent and app terms and conditions as understandable as possible (via dialogue from the CA in addition to the standard legal text displayed in all apps) it is possible that users could accept without fully understanding data will be used for analysis. Nonetheless, users always have the right to request the deletion of their data at any point in time.

\section{Study Design}

Elena + functions as a single-arm interventional study, whereby individuals' self-reported health assessment outcomes (see Table 3), the user-selected behavioral intentions at the end of each coaching session, and self-reported actual behaviors (see Table 4) are recorded as the core health and behavioral outcomes
TABLE 5 | Summary selection of marker variables.

\begin{tabular}{|c|c|}
\hline Marker variable & Explanation \\
\hline Literacy marker & Whether an individual is confused or not \\
\hline Sedentary marker & Whether an individual is sedentary or not \\
\hline Anxiety marker & $\begin{array}{l}\text { Whether an individual is currently experiencing anxiety or } \\
\text { not }\end{array}$ \\
\hline Depression marker & Whether an individual is currently feels depressed or not \\
\hline Weight marker & $\begin{array}{l}\text { Whether an individual is reports struggling with their } \\
\text { weight or not }\end{array}$ \\
\hline Sleep Marker & $\begin{array}{l}\text { Whether an individual is reports struggling with their } \\
\text { sleep patterns or not }\end{array}$ \\
\hline Humor marker & $\begin{array}{l}\text { Whether an individual is engages in humor with the CA } \\
\text { or not }\end{array}$ \\
\hline More coaching marker & $\begin{array}{l}\text { Whether an individual indicates desire for more coaching } \\
\text { on a specific topic or not }\end{array}$ \\
\hline Devices marker & $\begin{array}{l}\text { Whether an individual uses many electronic devices or } \\
\text { not }\end{array}$ \\
\hline Loneliness marker & Whether an individual is currently feels lonely or not \\
\hline Smoker marker & Whether an individual smokes tobacco or not \\
\hline
\end{tabular}

of interest. Additionally, we also collect ratings of the app usage experience, social demographic information and "marker variables" (i.e., user choices within the dialogues detailing the patient profile/usage experience objectively) shown in Table 5. Socio-demographic data is collected during first usage and before fifth subtopic completion, usage evaluations on a randomized basis after topic completion, and "marker" variables across all dialogues. Marker variables can be used to detail the user profile and usage experience, for example when a participant replies to coach that they do not understand terms used and need further explanation, this is saved as health literacy marker variable. Alternatively, if a user chooses to ask the CA for a joke, this choice is saved as a humor marker variable. As Elena+ has no control group, the authors plan to examine how individual attainment changes based on variations of app usage patterns and user profile over time.

\section{Methods}

To meet the project research aims, we will utilize panel data methods to track changes in health outcome scores gathered at 
baseline (i.e., after a topic has been selected but no coaching content has been completed yet) compared with follow-up intervals as individuals continue to use the app (timing specified in Table 4). To do this we will specify Auto-Regressive Moving Average (ARMA) models (152), whereby: (i) health outcome assessment scores are regressed on time, (ii) health outcome assessment scores are regressed on time, with no. of coaching subtopics completed specified as a moderating variable, (iii) health outcome assessment scores are regressed on time, with user selected behavioral intentions and user reported actual behaviors specified as serial mediators. A practical example of this would be examining whether setting intentions and reporting actual behaviors of abstaining from electronic devices before bed serially mediates the relationship between time spent using the app and lower scores for the Insomnia Severity Index.

Should sufficient observations be gathered, it may also be possible to adapt the aforementioned models and make forecasts based upon functions of past independent variable value(s) and/or past errors, as well as the present time error (153). In this case we would divide the dataset into training and test datasets, specify the ARMA model on training data, and compare its efficacy on test data. If suitable fit is found, the model may be used to make predictions (as to the impact of time spent using the app/no. of coaching subtopics completed/no. of intentions/actual behaviors reported) and their impact on health assessment scores. Additional analyses may include using socio-demographic and marker variables as inputs in Cluster Analyses such as Supervised k-Means Clustering (154) whereby individuals are grouped into sub-populations based upon health assessment scores and marker variables selected while using the app. In such a manner, it would be possible to identify aspects of the usage experience (for example, selection of humor marker variables, indicative of greater user engagement) that are linked to superior health outcome assessments.

\section{Intervention Timeframe}

The Elena+ intervention timeframe is estimated to last for approximately half a year if individuals complete all intervention content, as well as all subsequent assessments and actual behavior monitoring questions. However, the time to complete all content fully depends upon how quickly individuals complete all coaching sessions, and the subsequent assessments and actual behavior questions that are triggered by completing coaching sessions. The schedule of follow up health assessments and actual behaviors questions is given in Table 4. We utilize some "intervention jitter" (i.e., variation in timing of follow-up questions after coaching sessions) so that assessments are less likely to co-occur on the same day and that the potential burden for users is lessened. For example, for the anxiety topic health outcome assessments occur from 14 days after the first anxiety coaching session, and actual behavior questions 7 days.

\section{OUTLOOK}

At the time of writing, Elena+ is available in three language versions: (i) English (in Switzerland, Ireland, the United Kingdom, and the United States), European Spanish (in
Spain) and Latin American Spanish (in Mexico and Colombia) with data collection on going. Finished translations have been created for Tamil which will be launched in India, Sri Lanka, and Singapore. Work is also pending to improve server infrastructure which currently has capacity for 2,000 users.

Moving forward, increasing the effectiveness of Elena+ around the world may comprise of adapting and improving coaching content, features and visual aesthetics, for example, making cultural adaptations to match the profile of users in new launch countries. With the help of a sponsor, it could be possible to strengthen the social motivation for using Elena + by having gamified hearts redeemable for certain medical equipment (for example, winning hearts providing a donation of money to supply personal protective equipment or ventilators to atrisk areas). In a similar vein, understanding the "state of receptivity" $(155,156)$ of participants and sending reminders and notifications at the correct moment may represent a fruitful research direction. Post-pandemic, Elena+ intervention materials may also be adapted to function as a type of digital control condition for other digital health interventions, which would help measure the degree of change attributed to the design choices of a specific digital treatment tailored to a certain disease content against a general lifestyle digital intervention. Researchers may then be able to assess the efficacy of their treatment, over and above the effect of simply using any type of digital tool.

Elena+ intervention content is available under the Creative Commons license 4.0 CC BY-NC-SA, and MobileCoach (the underlying software for Elena+) is available under the Apache 2 license. Materials have been made available to help foster a dynamic research community around Elenat, so that researchers can utilize, adapt, and build on our content, working autonomously in new contexts to add new features/contents whilst sharing findings with other intervention authors. To this end, a collaboration has begun with colleagues from Dartmouth College in the United States to adapt elements of Elena+ into a "just-in-time-adaptive intervention" (157) whereby sensor data (such as GPS location, date and time, WiFi connection status) is utilized to match phone notifications to user state of receptivity (156). Additionally, discussions are underway with colleagues from Singapore-ETH Centre to build upon Elena+ dialogues for use in studies preventing type-2 diabetes and depression at the population-level. Further interested collaborators are warmly invited to contact the authors for further collaboration opportunities.

\section{CONCLUDING THOUGHTS}

Taken in total then, Elena + represents a highly innovative digital health intervention developed at speed during the COVID19 coronavirus pandemic to deliver pandemic lifestyle care. In the long term, Elena is not envisioned to be a static intervention, but rather an intervention which will evolve and adapt, leveraging the revolutionary potential of digital health to learn, innovate and apply solutions (30). Results will demonstrate areas of successes of the tool, as well as how improvements 
can be added to improve effectiveness of this and other future digital health interventions. These findings may be particularly applicable to other population-level threats to public health moving forward, such as obesity epidemic (158), and contribute to a greater understanding of digital health interventions for public health promotion.

\section{ETHICS STATEMENT}

The studies involving human participants were reviewed and approved by ETH Zurich, Zurich, Switzerland. The patients/participants provided their written informed consent to participate in this study.

\section{AUTHOR CONTRIBUTIONS}

All authors listed have made a substantial, direct and intellectual contribution to the to the Elena+ project, and have approved the paper for publication.

\section{REFERENCES}

1. World Health Organization. Coronavirus Disease 2019 (COVID-19): Situation Report, 67. Geneva: World Health Organization (2020).

2. Chua MSQ, Lee JCS, Sulaiman S, Tan HK. From the frontlines of COVID-19 - how prepared are we as obstetricians: a commentary. BJOG An Int J Obstet Gynaecol. (2020) 127:1041. doi: 10.1111/1471-0528.16254

3. Weng PY, Chiang YC. Psychological restoration through indoor and outdoor leisure activities. J Leis Res. (2014) 46:203-217. doi: 10.1080/00222216.2014.11950320

4. Javed B, Sarwer A, Soto EB, Mashwani Z-R. Impact of SARS-CoV-2 (coronavirus) pandemic on public mental health. Front Public Heal. (2020) 8:292. doi: $10.3389 /$ fpubh.2020.00292

5. Lin Y, Hu Z, Alias H, Wong LP. Knowledge, attitudes, impact, and anxiety regarding COVID-19 infection among the public in China. Front Public Heal. (2020) 8:236. doi: 10.3389/fpubh.2020.00236

6. Wilson JF. The crucial link between literacy and health. Ann Intern Med. (2003) 139:875-878. doi: 10.7326/0003-4819-139-10-200311180-00038

7. Baumer Y, Farmer N, Premeaux TA, Wallen GR, Powell-Wiley TM. Health disparities in COVID-19: addressing the role of social determinants of health in immune system dysfunction to turn the tide. Front Public Heal. (2020) 8:589. doi: $10.3389 /$ fpubh.2020.559312

8. Wong JEL, Leo YS, Tan CC. COVID-19 in Singapore-current experience. JAMA. (2020) 323:1243. doi: 10.1001/jama.2020.2467

9. Fiordelli M, Diviani N, Schulz PJ. Mapping mhealth research: a decade of evolution. J Med Internet Res. (2013) 15:e95. doi: 10.2196/jmir.2430

10. Laranjo L, Dunn AG, Tong HL, Kocaballi AB, Chen J, Bashir R, et al. Conversational agents in healthcare: a systematic review. $J$ Am Med Informatics Assoc. (2018) 25:1248-1258. doi: 10.1093/jamia/ ocy 072

11. Schachner T, Keller R, v Wangenheim F. Artificial intelligence-based conversational agents for chronic conditions: systematic literature review. J Med Internet Res. (2020) 22:e20701. doi: 10.2196/20701

12. Tudor Car L, Dhinagaran DA, Kyaw BM, Kowatsch T, Joty S, Theng YL, et al. Conversational agents in health care: scoping review and conceptual analysis. J Med Internet Res. (2020) 22:e17158. doi: 10.2196/ 17158

13. Kowatsch T, Nißen M, Shih C-HI, Rüegger D, Volland D, Filler A, et al. Textbased healthcare chatbots supporting patient and health professional teams: preliminary results of a randomized controlled trial on childhood obesity. In: Persuasive Embodied Agents for Behavior Change (PEACH2017), Stockholm, Sweden, August 27, 2017. Stockholm, Sweden: ETH Zurich.

\section{FUNDING}

This research was supported by the National Research Foundation, Prime Minister's Office, Singapore under its Campus for Research Excellence and Technological Enterprise (CREATE) programme.

\section{ACKNOWLEDGMENTS}

Part of this research was conducted at the Future Health Technologies programme at the Singapore-ETH Centre, which was established collaboratively between ETH Zurich and the National Research Foundation Singapore.

\section{SUPPLEMENTARY MATERIAL}

The Supplementary Material for this article can be found online at: https://www.frontiersin.org/articles/10.3389/fpubh. 2021.625640/full\#supplementary-material

14. Fadhil A, Villafiorita A. An adaptive learning with gamification \& conversational UIs. In: Adjun Publ 25th Conf User Model Adapt Pers - UMAP '17. (2017). p. 408-412.

15. Provoost S, Lau HM, Ruwaard J, Riper H. Embodied conversational agents in clinical psychology: a scoping review. J Med Internet Res. (2017) 19:e151. doi: 10.2196/jmir.6553

16. Hauser-Ulrich S, Künzli H, Meier-Peterhans D, Kowatsch T. A smartphonebased health care chatbot to promote self-management of chronic pain (SELMA): pilot randomized controlled trial. JMIR mHealth uHealth. (2020) 8:1-23. doi: $10.2196 / 15806$

17. Fitzpatrick KK, Darcy A, Vierhile M. Delivering cognitive behavior therapy to young adults with symptoms of depression and anxiety using a fully automated conversational agent (Woebot): a randomized controlled trial. JMIR Ment Heal. (2017) 4:e19. doi: 10.2196/menta 1.7785

18. Kretzschmar K, Tyroll H, Pavarini G, Manzini A, Singh I, NeurOx Young People's Advisory G. Can your phone be your therapist? Young people's ethical perspectives on the use of fully automated conversational agents (chatbots) in mental health support. Biomed Inf Insights. (2019) 11:117822261982908. doi: 10.1177/1178222619829083

19. Stieger M, Nißen M, Rüegger D, Kowatsch T, Flückiger C, Allemand M. PEACH, a smartphone- and conversational agent-based coaching intervention for intentional personality change: study protocol of a randomized, wait-list controlled trial. BMC Psychol. (2018) 6:1-15. doi: 10.1186/s40359-018-0257-9

20. Lennon MR, Bouamrane MM, Devlin AM, O'Connor S, O’Donnell C, Chetty $U$, et al. Readiness for delivering digital health at scale: lessons from a longitudinal qualitative evaluation of a national digital health innovation program in the United Kingdom. J Med Internet Res. (2017) 19:1-18. doi: 10.2196/jmir.6900

21. Hostetter M, Klein S, McCarthy D. Taking Digital Health to the Next Level. New York, NY: The Commonwealth Fund (2014).

22. Ross WR. Promoting health equity: a new challenge for frontiers in public health. Front Public Heal. (2013) 1:27. doi: 10.3389/fpubh.2013.00027

23. Rabel M, Laxy M, Thorand B, Peters A, Schwettmann L, Mess F. Clustering of health-related behavior patterns and demographics. Results from the population-based KORA S4/F4 cohort study. Front Public Heal. (2019) 6:387. doi: $10.3389 /$ fpubh.2018.00387

24. Dolley S. Big data's role in precision public health. Front Public Heal. (2018) 6:1. doi: 10.3389/fpubh.2018.00068

25. Brommels M. Patient segmentation: adjust the production logic to the medical knowledge applied and the patient's ability to 
self-manage-a discussion paper. Front Public Heal. (2020) 8:195. doi: $10.3389 /$ fpubh.2020.00195

26. Ajzen I. The Theory of Planned Behavior. Amherst: Academic Press, Inc. (1991).

27. Davis FD. Perceived usefulness, perceived ease of use, and user acceptance of information technology. Mis Q. (1989) 13:319-40. doi: 10.2307/249008

28. Risling T, Martinez J, Young J, Thorp-Froslie N. Evaluating patient empowerment in association with ehealth technology: scoping review. J Med Internet Res. (2017) 19:e329. doi: 10.2196/jmir.7809

29. Passmore J, Oades L. Positive psychology coaching: a model for coaching practice. Coach Psychol. (2014) 10:68-70. Available online at: http://centaur. reading.ac.uk/81943/

30. Kostkova P. Grand challenges in digital health. Front Public Heal. (2015) 3:134. doi: 10.3389/fpubh.2015.00134

31. Castonguay LG, Constantino MJ, Holtforth MG. The working alliance: where are we and where should we go? Psychotherapy. (2006) 43:2719. doi: 10.1037/0033-3204.43.3.271

32. Bickmore T, Gruber A, Picard R. Establishing the computer-patient working alliance in automated health behavior change interventions. Patient Educ Couns. (2005) 59:21-30. doi: 10.1016/j.pec.2004.09.008

33. Koole SL, Tschacher W. Synchrony in psychotherapy: a review and an integrative framework for the therapeutic alliance. Front Psychol. (2016) 7:14. doi: $10.3389 /$ fpsyg. 2016.00862

34. Munder T, Wilmers F, Leonhart R, Linster HW, Barth J. Working alliance inventory-short revised (WAI-SR): psychometric properties in outpatients and inpatients. Clin Psychol Psychother. (2010) 17:2319. doi: $10.1002 /$ cpp. 658

35. Kiluk BD, Serafini K, Frankforter T, Nich C, Carroll KM. Only connect: the working alliance in computer-based cognitive behavioral therapy. Behav Res Ther. (2014) 63:139-46. doi: 10.1016/j.brat.2014.10.003

36. Anstiss A, Anstiss T, Passmore J. Dr. Jonathan Passmore's Publications Library: Motivational Interviewing. London: Taylor \& Francis Ltd (2012).

37. Passmore J, Peterson DB, Freire T. The psychology of coaching and mentoring. In: Passmore J, Peterson DB, Freire T, editors. Wiley-Blackwell Handb Psychol Coach Mentor. Chichester: John Wiley \& Sons (2012). p. 1-11.

38. Kowatsch T, Nißen M, Rüegger D, Stieger M, Flückiger C, Allemand M, et al. The Impact of Interpersonal Closeness Cues in Text-based Healthcare Chatbots on Attachment Bond and the Desire to Continue Interacting: An Experimental Design. Portsmouth: Twenty - Sixth European Conference on Information Systems (ECIS2018) (2018).

39. Mack R, Breckon J, Butt J, Maynard I. Exploring the understanding and application of motivational interviewing in applied sport psychology. Sport Psychol. (2017) 31:396-409. doi: 10.1123/tsp.201 6-0125

40. Passmore J, Peterson D, Freire T. The Wiley-Blackwell Handbook of the Psychology of Coaching and Mentoring. Oxford: John Wiley \& Sons (2016).

41. Passmore J, Peterson D, Freire T. Psychology of coaching mentoring. In: Passmore J, Peterson D, Freire T, editors. Wiley-Blackwell Handbook of the Psychology of Coaching \& Mentoring. Oxford: Wiley-Blackwell (2013). p. 1-11.

42. Bickmore T, Cassell J. Small talk and conversational storytelling in embodied conversational interface agents. In: Proc AAAI Fall Symp Narrat Intell. (1999). p. 87-92.

43. Ma T. Virtual Humans in Health-Related Interventions: A Meta-Analysis. Glasgow: Extended Abstracts of the 2019 CHI Conference on Human Factors in Computing Systems (2019).

44. Elkins AC, Derrick DC, Burgoon JK, Nunamaker JF. Predicting users' perceived trust in embodied conversational agents using vocal dynamics. In: Proc Annu Hawaii Int Conf Syst Sci. (2012) p. 579-588.

45. Sardi L, Idri A, Fernández-Alemán JL. A systematic review of gamification in e-Health. J Biomed Inform. (2017) 71:31-48. doi: 10.1016/j.jbi.2017.05.011

46. Bickmore T, Schulman D, Yin L. Engagement vs. Deceit: Virtual Humans with Human Autobiographies. Berlin: Springer (2009).

47. Komiak S, Benbasat I. The effects of personalization and familiarity on trust and adoption of recommendation agents. MIS Q. (2006) 30:94160. doi: $10.2307 / 25148760$

48. Danckwerts S, Meißner L, Krampe C. Examining user experience of conversational agents in hedonic digital services - antecedents and the role of psychological ownership. J Serv Manag Res. (2019) 3:11125. doi: 10.15358/2511-8676-2019-3-111

49. Ryan RM, Deci EL. Self-Determination Theory: Basic Psychological Needs in Motivation, Development, and Wellness. New York, NY, US: Guilford Press (2017).

50. Miller WR, Rollnick S. Motivational Interviewing: Helping People Change. New York, NY: Guilford press (2012).

51. Martins RK, McNeil DW. Review of motivational interviewing in promoting health behaviors. Clin Psychol Rev. (2009) 29:283-93. doi: 10.1016/j.cpr.2009.02.001

52. Fleming TM, Bavin L, Stasiak K, Hermansson-Webb E, Merry SN, Cheek C, et al. Serious games and gamification for mental health: current status and promising directions. Front Psychiatry. (2016) 7:215. doi: $10.3389 /$ fpsyt.2016.00215

53. Chou Y. Actionable Gamification: Beyond Points, Badges, and Leaderboards. Birmingham: Packt Publishing Ltd. (2019).

54. Liu D, Santhanam R, Webster J. Toward meaningful engagement: a framework for design and research of gamified information systems. Mis $Q$. (2017) 41:1011-34. doi: 10.25300/MISQ/2017/41.4.01

55. King D, Greaves F, Exeter C, Darzi A. "Gamification": influencing health behaviours with games. $J \quad R \quad$ Soc Med. (2013) 106:768. doi: $10.1177 / 0141076813480996$

56. Morgan DL. Schedules of reinforcement at 50: a retrospective appreciation. Psychol Rec. (2010) 60:151-72. doi: 10.1007/BF03395699

57. Schwartz SH, Howard JA.Internalized values as motivators of altruism. In: Development and Maintenance of Prosocial Behavior. Boston, MA: Springer (1984). p. 229-55.

58. Ma WWK, Chan A. Knowledge sharing and social media: altruism, perceived online attachment motivation, and perceived online relationship commitment. Comput Human Behav. (2014) 39:51-8. doi: 10.1016/j.chb.2014.06.015

59. Erspective LOP, Lusch RF. Service innovation: a service-dominant-logic perspective. Mis Q. (2015) 39:155-75. doi: 10.25300/MISQ/2015/39.1.07

60. Udo GJ, Bagchi KK, Kirs PJ. An assessment of customers' e-service quality perception, satisfaction and intention. Int J Inf Manage. (2010) 30:48192. doi: 10.1016/j.ijinfomgt.2010.03.005

61. Zablah AR, Sirianni NJ, Korschun D, Gremler DD, Beatty SE. Emotional convergence in service relationships: the shared frontline experience of customers and employees. J Serv Res. (2017) 20:76-90. doi: 10.1177/1094670516675405

62. Habel J, Alavi S, Schmitz C, Schneider JV, Wieseke J. When do customers get what they expect? Understanding the ambivalent effects of customers' service expectations on satisfaction. J Serv Res. (2016) 19:36179. doi: 10.1177/1094670516662350

63. Arigo D, Pagoto S, Carter-Harris L, Lillie SE, Nebeker C. Using social media for health research: methodological and ethical considerations for recruitment and intervention delivery. Digit Heal. (2018) 4:205520761877175. doi: 10.1177/2055207618771757

64. Korda H, Itani Z. Harnessing social media for health promotion and behavior change. Health Promot Pract. (2013) 14:1523. doi: $10.1177 / 1524839911405850$

65. Nutbeam D, Kickbusch I. Health promotion glossary. Health Promot Int. (1998) 13:349-64. doi: 10.1093/heapro/13.4.349

66. Kutcher S, Wei Y, Coniglio C. Mental health literacy: past, present, and future. Can J Psychiatry. (2016) 61:154-8. doi: 10.1177/0706743715616609

67. Batterham RW, Hawkins M, Collins PA, Buchbinder R, Osborne RH. Health literacy: applying current concepts to improve health services and reduce health inequalities. Public Health. (2016) 132:312. doi: 10.1016/j.puhe.2016.01.001

68. Coleman CA, Hudson S, Maine LL. Health literacy practices and educational competencies for health professionals: a consensus study. J Health Commun. (2013) 18:82-102. doi: 10.1080/10810730.2013.8 29538

69. Schapira MM, Swartz S, Ganschow PS, Jacobs EA, Neuner $\mathrm{JM}$, Walker CM, et al. Tailoring educational and behavioral interventions to level of health literacy: a systematic review. $M D M$ Policy Pract. (2017) 2:238146831771447. doi: 10.1177/23814683177 14474 
70. Crook B, Stephens KK, Pastorek AE, Mackert M, Donovan EE. Sharing health information and influencing behavioral intentions: the role of health literacy, information overload, and the internet in the diffusion of healthy heart information. Health Commun. (2016) 31:60-71. doi: 10.1080/10410236.2014.936336

71. Osborn CY, Paasche-Orlow MK, Bailey SC, Wolf MS. The mechanisms linking health literacy to behavior and health status. Am J Health Behav. (2011) 35:118-28. doi: 10.5993/AJHB.35.1.11

72. Passmore J, Fillery-Travis A. A critical review of executive coaching research: a decade of progress and what's to come. Coaching. (2011) 4:7088. doi: 10.1080/17521882.2011.596484

73. Gross JJ. Handbook of Emotion Regulation. New York, NY: Guilford publications (2013).

74. Passmore J. Motivational interviewing techniques reflective listening. Coach Psychol. (2011) 7:49-52. Available online at: http://jonathanpassmore. com/wp-content/uploads/resources/Passmore\%20(2011)\%20Motivational \%20Interviewing\%20Techniques-\%20Reflective\%20listening.pdf

75. Mann T, de Ridder D, Fujita K. Self-regulation of health behavior: social psychological approaches to goal setting and goal striving. Heal Psychol. (2013) 32:487-98. doi: 10.1037/a0028533

76. West SP, Lagua C, Trief PM, Izquierdo R, Weinstock RS. Goal setting using telemedicine in rural underserved older adults with diabetes: experiences from the informatics for diabetes education and telemedicine project. Telemed eHealth. (2010) 16:405-16. doi: 10.1089/tmj.2009.0136

77. Michie S, van Stralen MM, West R. The behaviour change wheel: a new method for characterising and designing behaviour change interventions. Implement Sci. (2011) 6:42. doi: 10.1186/1748-5908-6-42

78. Sheeran P, Webb TL. The intention-behavior gap. Soc Personal Psychol Compass. (2016) 10:503-18. doi: 10.1111/spc3.12265

79. White SS, Schneider B. Climbing the commitment ladder: the role of expectations disconfirmation on customers' behavioral intentions. J Serv Res. (2000) 2:240-53. doi: 10.1177/109467050023002

80. Inauen J, Shrout PE, Bolger N, Stadler G, Scholz U. Mind the gap? An intensive longitudinal study of between-person and withinperson intention-behavior relations. Ann Behav Med. (2016) 50:51622. doi: 10.1007/s12160-016-9776-x

81. Berli C, Stadler G, Inauen J, Scholz U. Action control in dyads: a randomized controlled trial to promote physical activity in everyday life. Soc Sci Med. (2016) 163:89-97. doi: 10.1016/j.socscimed.2016.07.003

82. Fennis BM, Adriaanse MA, Stroebe W, Pol B. Bridging the intentionbehavior gap: inducing implementation intentions through persuasive appeals. J Consum Psychol. (2011) 21:302-11. doi: 10.1016/j.jcps.2010.12.003

83. Schwerdtfeger AR, Schmitz C, Warken M. Using text messages to bridge the intention-behavior gap? A pilot study on the use of text message reminders to increase objectively assessed physical activity in daily life. Front Psychol. (2012) 3:1-9. doi: 10.3389/fpsyg.2012.00270

84. Zhang CQ, Zhang R, Schwarzer R, Hagger MS. A meta-analysis of the health action process approach. Heal Psychol. (2019) 38:62337. doi: $10.1037 /$ hea 0000728

85. Schwarzer R. Modeling health behavior change: how to predict and modify the adoption and maintenance of health behaviors. Appl Psychol. (2008) 57:1-29. doi: 10.1111/j.1464-0597.2007.00325.x

86. Haslam N, Holland E, Kuppens P. Categories versus dimensions in personality and psychopathology: a quantitative review of taxometric research. Psychol Med. (2012) 42:903-20. doi: 10.1017/S00332917110 01966

87. Waszczuk MA, Zimmerman M, Ruggero C, Li K, MacNamara A, Weinberg A, et al. What do clinicians treat: diagnoses or symptoms? The incremental validity of a symptom-based, dimensional characterization of emotional disorders in predicting medication prescription patterns. Compr Psychiatry. (2017) 79:80-8. doi: 10.1016/j.comppsych.2017.04.004

88. Dalgleish T, Black M, Johnston D, Bevan A. Transdiagnostic approaches to mental health problems: current status and future directions. J Consult Clin Psychol. (2020) 88:179-95. doi: 10.1037/ccp0000482

89. Allington D, Dhavan N. The Relationship Between Conspiracy Beliefs and Compliance With Public Health Guidance With Regard to COVID-19. (2020). Available online at: http://kclpure.kcl.ac.uk/portal/files/127048253/ Allington_and_Dhavan_2020.pdf (accessed April 23, 2020).
90. Kelly RB, Zyzanski SJ, Alemagno SA. Prediction of motivation and behavior change following health promotion: role of health beliefs, social support, and self-efficacy. Soc Sci Med. (1991) 32:311-20. doi: 10.1016/0277-9536(91)90109-P

91. Chen ZF, Cheng Y. Consumer response to fake news about brands on social media: the effects of self-efficacy, media trust, and persuasion knowledge on brand trust. J Prod Brand Manag. (2019) 29:18898. doi: 10.1108/JPBM-12-2018-2145

92. World Health Organization. Considerations for Quarantine of Individuals in the Context of Containment for Coronavirus Disease (COVID-19): Interim Guidance-2. (2020). Available online at: https://www.who.int/news(accessed April 23, 2020).

93. Treiber FA, Baranowski T, Braden DS, Strong WB, Levy M, Knox W. Social support for exercise: relationship to physical activity in young adults. Prev Med. (1991) 20:737-50. doi: 10.1016/0091-7435(91)90068-F

94. Resnick B, Orwig D, Magaziner J, Wynne C. The effect of social support on exercise behavior in older adults. Clin Nurs Res. (2002) 11:5270. doi: $10.1177 / 105477380201100105$

95. Imeri L, Opp MR. How (and why) the immune system makes us sleep. Nat Rev Neurosci. (2009) 10:199-210. doi: 10.1038/nrn2576

96. Alvaro PK, Roberts RM, Harris JK. A systematic review assessing bidirectionality between sleep disturbances, anxiety, and depression. Sleep. (2013) 36:1059-68. doi: 10.5665/sleep.2810

97. Barber MI. Sleep in a time of pandemic-a position statement from the national sleep foundation. Sleep Heal. 6:431. doi: 10.1016/j.sleh.2020.05.003

98. Giuntella O, Hyde K, Saccardo S, Sadoff S. Lifestyle and mental health disruptions during COVID-19. SSRN Electron J. (2020) 118:e2016632118. doi: 10.1073/pnas.2016632118

99. Morgenthaler TI, Owens J, Alessi C, Boehlecke B, Brown TM, Coleman J, et al. Practice parameters for behavioral treatment of bedtime problems and night wakings in infants and young children. Sleep. (2006) 29:1277-81.

100. Gee B, Orchard F, Clarke E, Joy A, Clarke T, Reynolds S. The effect of non-pharmacological sleep interventions on depression symptoms: a metaanalysis of randomised controlled trials. Sleep Med Rev. (2019) 43:11828. doi: 10.1016/j.smrv.2018.09.004

101. Montgomery P, Dennis J. A systematic review of non-pharmacological therapies for sleep problems in later life. Sleep Med Rev. (2004) 8:4762. doi: 10.1016/S1087-0792(03)00026-1

102. Arns M, Gunkelman J, Olbrich S, Sander C, Hegerl U. CHAPTER 44 c0004 EEG Vigilance and Phenotypes in Neuropsychiatry: Implications for Intervention (2011) 434-435:79-435

103. Borbély AA, Daan S, Wirz-Justice A, Deboer T. The two-process model of sleep regulation: a reappraisal. J Sleep Res. (2016) 25:13143. doi: $10.1111 /$ jsr.12371

104. Akçay BD, Akçay D, Yetkin S. The effects of mobile electronic devices use on the sleep states of university students. Anatol J Psychiatry. (2020) 21:1. doi: 10.5455/apd.99831

105. Lanham-New SA, Hill TR, Gallagher AM, Vorster HH. Introduction to Human Nutrition. Hoboken, NJ: John Wiley \& Sons (2019).

106. Lawrence M, Worsley T. Public Health Nutrition. Crows Nest: McGraw-Hill Education (UK) (2007).

107. Jastran MM, Bisogni CA, Sobal J, Blake C, Devine CM. Eating routines. Embedded, value based, modifiable, and reflective. Appetite. (2009) 52:12736. doi: $10.1016 /$ j.appet.2008.09.003

108. World Health Organization. Healthy Diet. Cairo: World Health Organization. Regional Office for the Eastern Mediterranean (2019).

109. Trapp CB, Barnard ND. Usefulness of Vegetarian and Vegan Diets for Treating Type 2 Diabetes. Washington, DC: Springer (2010).

110. McDougall J, Thomas LE, McDougall C, Moloney G, Saul B, Finnell JS, et al. Effects of 7 days on an ad libitum low-fat vegan diet: the McDougall program cohort. Nutr J. (2014) 13:1-7. doi: 10.1186/1475-2891-13-99

111. Rogerson D. Vegan diets: practical advice for athletes and exercisers. $J$ Int Soc Sports Nutr. (2017) 14:1-15. doi: 10.1186/s12970-0170192-9

112. Pfefferbaum B, North CS. Mental health and the Covid-19 pandemic. N Engl J Med. (2020) 383:510-2. doi: 10.1056/NEJMp2008017

113. Usher K, Durkin J, Bhullar N. The COVID-19 pandemic and mental health impacts. Int J Ment Health Nurs. (2020) 29:315-8. doi: 10.1111/inm.12726 
114. Park S, Choi J, Lee S, Oh C, Kim C, La S, et al. Designing a chatbot for a brief motivational interview on stress management: qualitative case study. J Med Internet Res. (2019) 21:e12231. doi: 10.2196/12231

115. Cuijpers P, Cristea IA, Karyotaki E, Reijnders M, Hollon SD. Component studies of psychological treatments of adult depression: a systematic review and meta-analysis. Psychother Res. (2019) 29:15-29. doi: 10.1080/10503307.2017.1395922

116. DeRubeis RJ, Keefe JR, Beck AT. Cognitive Therapy. New York, NY: The Guilford Press (2019).

117. Wilkins G, Andrews G, Bell C, Boyce P, Gale C, Rapee R, et al. Managing anxiety disorders in adults. Med Today. (2019) 20:12-22. Available online at: https://medicinetoday.com.au/mt/december-2019

118. Sanderson WC, Funk AP, Ginsburg KL, Limowski AR, Olesnycky OS. Coping with Fear and Sadness During a Pandemic. New York, NY: Hofstra University (2020).

119. Peplau LA. Loneliness research: basic concepts and findings. In: Sarason IG, Sarason BR, editors. Social Support: Theory, Research and Applications. Dordrecht: Springer Netherlands (1985). p. 269-286.

120. Cacioppo JT, Cacioppo S. The growing problem of loneliness. Lancet. (2018) 391:426. doi: 10.1016/S0140-6736(18)30142-9

121. Holt-Lunstad J. The potential public health relevance of social isolation and loneliness: prevalence, epidemiology, and risk factors. Public Policy Aging Rep. (2017) 27:127-30. doi: 10.1093/ppar/prx030

122. Social Isolation and Loneliness in Older Adults. Washington, DC: National Academies Press (2020).

123. Cacioppo S, Grippo AJ, London S, Goossens L, Cacioppo JT. Loneliness: clinical import and interventions. Perspect Psychol Sci. (2015) 10:23849. doi: $10.1177 / 1745691615570616$

124. Golden J, Conroy RM, Bruce I, Denihan A, Greene E, Kirby M, et al. Loneliness, social support networks, mood and wellbeing in community-dwelling elderly. Int J Geriatr Psychiatry. (2009) 24:694700. doi: 10.1002/gps.2181

125. Bouman TK. Relationship between the pleasant events schedule and other aspects of psychopathology. Artic J Abnorm Psychol. (1986) 95:3737. doi: 10.1037/0021-843X.95.4.373

126. Katz MR, Rodin G, Devins GM. Self-esteem and cancer: theory and research. Can J Psychiatry. (1995) 40:608-15. doi: 10.1177/070674379504001007

127. Thoits PA. Stress, coping, and social support processes: where are we? What next? J Health Soc Behav. (1995) 35:53-79. doi: 10.2307/2626957

128. Lazarus RS, Folkman S. Stress, Appraisal, and Coping. New York, NY: Springer Publishing Company (1984).

129. Bandura A. Self-efficacy: the exercise of control. Choice Rev Online. (1997) 35:35.1826. doi: 10.5860/CHOICE.35-1826

130. Horvath AO, Greenberg LS. Development and validation of the working alliance inventory. J Couns Psychol. (1989) 36:223-33. doi: 10.1037/0022-0167.36.2.223

131. Edwards EA, Lumsden J, Rivas C, Steed L, Edwards LA, Thiyagarajan $A$, et al. Gamification for health promotion: systematic review of behaviour change techniques in smartphone apps. BMJ Open. (2016) 6:e012447. doi: 10.1136/bmjopen-2016-012447

132. Solomon MR, Surprenant C, Czepiel JA, Gutman EG. A role theory perspective on dyadic interactions: the service encounter. J Mark. (1985) 49:99-111. doi: 10.1177/002224298504900110

133. Cardoso M. The Onboarding Effect: Leveraging User Engagement and Retention in Crowdsourcing Platforms. Denver: CHI Conference Extended Abstracts on Human Factors in Computing Systems (2017).

134. Metzger MJ. Communication privacy management in electronic commerce. $J$ Comput Commun. (2007) 12:335-61. doi: 10.1111/j.1083-6101.2007.00328.x

135. World Health Organization, Regional Office for Europe. Health literacy: The Solid Facts. (2013). Available online at: http://www.euro.who.int/pubrequest (accessed September 10, 2020).

136. Gollwitzer PM. Implementation intentions: strong effects of simple plans. Am Psychol. (1999) 54:493-503. doi: 10.1037/0003-066X.54.7.493

137. Apache Software Foundation. Apache License, Version 2.0. (2004) Available online at: https://www.apache.org/licenses/LICENSE-2.0 (accessed September 21, 2020).
138. Kowatsch T, Volland D, Shih I, Rüegger D, Künzler F, Barata F, et al. Design and evaluation of a mobile chat app for the open source behavioral health intervention platform mobilecoach. In: Lecture Notes in Computer Science (including subseries Lecture Notes in Artificial Intelligence and Lecture Notes in Bioinformatics). Cham: Springer Verlag (2017). p. 485-9.

139. Filler A, Kowatsch T, Haug S, Wahle F, Staake T, Fleisch E. MobileCoach: a novel open source platform for the design of evidence-based, scalable and low-cost behavioral health interventions: overview and preliminary evaluation in the public health context. In: Wirel Telecommun Symp. (2015).

140. Beun RJ, Fitrianie S, Griffioen-Both F, Spruit S, Horsch C, Lancee J, et al. Talk and tools: the best of both worlds in mobile user interfaces for E-coaching. Pers Ubiquitous Comput. (2017) 21:661-74. doi: 10.1007/s00779-017-1021-5

141. Staples LG, Dear BF, Gandy M, Fogliati V, Fogliati R, Karin E, et al. Psychometric properties and clinical utility of brief measures of depression, anxiety, and general distress: the PHQ-2, GAD-2, and K-6. Gen Hosp Psychiatry. (2019) 56:13-8. doi: 10.1016/j.genhosppsych.2018. 11.003

142. Gerhold L. COVID-19: Risk Perception and Coping Strategies. Berlin: AG Interdisziplin4re Sicherheitsforschung (2020).

143. SAX Institute. Short Survey Instruments for Children's Diet and Physical Activity: The Evidence. (2016). Availableonline at: www.saxinstitute.org.au (accessed July 11, 2021).

144. Bastien $\mathrm{CH}$, Vallières $\mathrm{A}$, Morin $\mathrm{CM}$. Validation of the insomnia severity index as an outcome measure for insomnia research. Sleep Med. (2001) 2:297-307. doi: 10.1016/S1389-9457(00)00065-4

145. Spitzer RL, Kroenke K, Williams JBW, Löwe B. A brief measure for assessing generalized anxiety disorder: the GAD-7. Arch Intern Med. (2006) 166:10927. doi: 10.1001/archinte.166.10.1092

146. Neto F. Psychometric analysis of the short-form UCLA loneliness scale (ULS-6) in older adults. Eur J Ageing. (2014) 11:313-9. doi: 10.1007/s10433-014-0312-1

147. Milton K, Bull FC, Bauman A. Reliability and validity testing of a single-item physical activity measure. Br J Sports Med. (2011) 45:2038. doi: 10.1136/bjsm.2009.068395

148. YOUTHREX. Evaluation Measures International Physical Activity Questionnaire-Short Form. Toronto (2002).

149. Booth M. Assessment of physical activity: an international perspective. Res $Q$ Exerc Sport. (2000) 71:114-20. doi: 10.1080/02701367.2000.11082794

150. Sinclair VG, Wallston KA. The development and psychometric evaluation of the brief resilient coping scale. Assessment. (2004) 11:94-101. doi: 10.1177/1073191103258144

151. Kroenke, Kurt, Spitzer, Robert, Williams J. The patient health questionnaire2 : validity of a two-item depression screener. Med Care. (2003) 41:128492. doi: 10.1097/01.MLR.0000093487.78664.3C

152. Beveridge S, Oickle C. A comparison of Box-Jenkins and objective methods for determining the order of a non-seasonal ARMA model. J Forecast. (1994) 13:419-34. doi: 10.1002/for.3980130502

153. Box GEP, Jenkins GM, Reinsel GC, Ljung GM. Time Series Analysis: Forecasting and Control. Hoboken, NJ: John Wiley \& Sons (2015).

154. Finley T, Joachims T. Supervised clustering with support vector machines. In ICML 2005 - Proceedings of the 22nd International Conference on Machine Learning. p. 217-24.

155. Kramer J-NN, Künzler F, Mishra V, Presset B, Kotz D, Smith S, et al. Investigating intervention components and exploring states of receptivity for a smartphone app to promote physical activity: protocol of a microrandomized trial. JMIR Res Protoc. (2019) 8:e11540. doi: 10.2196/11540

156. Kunzler F, Mishra V, Kramer JN, Kotz D, Fleisch E, Kowatsch T. Exploring the state-of-receptivity for mhealth interventions. Proc ACM Interact Mobile Wearable Ubiquitous Technol. (2019) 3:1-27. doi: 10.1145/3369805

157. Nahum-Shani I, Smith SN, Spring BJ, Collins LM, Witkiewitz K, Tewari A, et al. Just-in-time adaptive interventions (JITAIs) in mobile health: key components and design principles for ongoing health behavior support. Ann Behav Med. (2016) 52:446-62. doi: 10.1007/s12160-016-9830-8

158. Berry EM. The obesity pandemic-whose responsibility? No blame, no shame, not more of the same. Front Nutr. (2020) 7:2. doi: 10.3389/fnut.2020.00002 
Conflict of Interest: JO, PS, AA, DR, CB, OK, EF, FW, and TK are affiliated with the Centre for Digital Health Interventions www.c4dhi.org, a joint initiative of the Department of Management, Technology and Economics at ETH Zurich and the Institute of Technology Management at the University of St. Gallen, which was funded in part by the Swiss health insurer CSS Versicherung. EF and TK are also cofounders of Pathmate Technologies, a university spinoff company that creates and delivers digital clinical pathways. However, neither CSS nor Pathmate Technologies are involved in the Elena+ project or this article.

The remaining authors declare that the research was conducted in the absence of any commercial or financial relationships that could be construed as a potential conflict of interest.

The reviewer AR declared a past co-authorship with several of the authors AS and $\mathrm{RB}$ to the handling editor.
Publisher's Note: All claims expressed in this article are solely those of the authors and do not necessarily represent those of their affiliated organizations, or those of the publisher, the editors and the reviewers. Any product that may be evaluated in this article, or claim that may be made by its manufacturer, is not guaranteed or endorsed by the publisher.

Copyright (c) 2021 Ollier, Neff, Dworschak, Sejdiji, Santhanam, Keller, Xiao, Asisof, Rüegger, Bérubé, Hilfiker Tomas, Neff, Yao, Alattas, Varela-Mato, Pitkethly, Vara, Herrero, Baños, Parada, Agatheswaran, Villalobos, Keller, Chan, Mishra, Jacobson, Stanger, He, von Wyl, Weidt, Haug, Schaub, Kleim, Barth, Witt, Scholz, Fleisch, Wangenheim, Car, Müller-Riemenschneider, Hauser-Ulrich, Asomoza, SalamancaSanabria, Mair and Kowatsch. This is an open-access article distributed under the terms of the Creative Commons Attribution License (CC BY). The use, distribution or reproduction in other forums is permitted, provided the original author(s) and the copyright owner(s) are credited and that the original publication in this journal is cited, in accordance with accepted academic practice. No use, distribution or reproduction is permitted which does not comply with these terms. 